\title{
Reply to "Guillain-Barré syndrome in the COVID-19 era another occasional cluster?": Insights from two distinct clusters of Guillain-Barré syndrome detected in Europe in the COVID-19 era
}

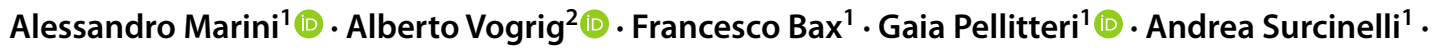 \\ Mariarosaria Valente ${ }^{1,2}$ (1) $\cdot$ Gian Luigi Gigli ${ }^{1,2,3}$
}

Received: 11 June 2020 / Accepted: 16 June 2020 / Published online: 4 August 2020

(c) Springer-Verlag GmbH Germany, part of Springer Nature 2020

\section{Dear Sirs,}

To date, 29 cases of Guillain-Barré syndrome (GBS) have been reported among patients with previous or concomitant diagnosis of SARS-CoV-2 infection [see references in Supplementary Material]. Even though no clear cause-effect relationship has been established yet, it is probable that both para- and post-infectious GBS represent neurological complications of COVID-19.

The negativity of microbiological tests for SARS-CoV-2 infection in both our patients [1] and those observed in two hospitals across the French-Swiss border during the 2020 March-April [2] render the establishment of a clear association with the COVID-19 pandemic impossible.

In terms of number of patients diagnosed with GBS and patients expected based on previous years, the cluster observed by Tatu is very similar to ours. In both reports, when comparing it to previous years, the almost fivefold

This reply refers to the letter to the editor published here: https:// link.springer.com/article/10.1007/s00415-020-10005-3

The original publication can be read here: https://link.springer. com/content/pdf/10.1007/s00415-020-09911-3

Electronic supplementary material The online version of this article (https://doi.org/10.1007/s00415-020-10006-2) contains supplementary material, which is available to authorized users.

Alessandro Marini

alemarini00@gmail.com

1 Neurology Unit, Department of Medicine (DAME), University of Udine, Piazzale Santa Maria della Misericordia 15, 33100 Udine, Italy

2 Clinical Neurology Unit, Misericordia University Hospital, Santa Maria della Misericordia University Hospital, Udine, Italy

3 DMIF, University of Udine, Udine, Italy increase in GBS incidence is impressive and deserves to be carefully evaluated.

When examining the serologic negativity of all but one of our patients, we hypothesized that the latter could have been the result of an insufficient sensitivity to the rapid (qualitative) serologic test. Unfortunately, other cases of GBS in patients with ascertained SARS-CoV-2 infection do not solve the dilemma. In fact, quantitative serologic tests were performed/available only in 4 out of 29 (14\%), all with positive results [3-6], while no data on qualitative rapid serologic assays were provided.

In general, sensitivity of serologic SARS-CoV-2 testing depends on the technique adopted and on other relevant factors:

(1) Abs directed against the S protein tend to appear later than those against the $\mathrm{N}$ protein. Therefore, $\mathrm{N}$ proteinbased assays are probably better in the acute phase, while S protein-based methods may be preferable with convalescent sera [7, 8];

(2) Certain diagnostic methods [e.g., enzyme-linked immunosorbent assays (ELISAs) and Western blot (WB) analysis] only use denatured linear forms of the S protein, meaning that correct folding and post-translational modifications (e.g., glycosylation) can be lost. Thus, patients harboring Abs recognizing conformational/ glycosylation-dependent epitopes could tested as false negatives using these techniques [8];

(3) Ab titer of both IgG and IgM has a large interindividual variability across SARS-CoV-2 patients [9]. Notably, patients have been documented having titers of neutralizing antibodies under the detectable level of the assay [10];

(4) Abs could be truly undetectable in some patients, the exact slope of the humoral immune response curve to this new virus being still unknown. However, this pos- 
sibility is unlikely given the previous experience with SARS-CoV, in which positive IgG titers were detected 2 years after the infection in almost $90 \%$ of cases [11].

Tatu et al. introduce one more possible explanation, suggesting that a contact with SARS-CoV-2 (without infection) could be a precipitating factor for an immunologic cascade that leads to GBS. If they mean that the nerve damage could be the effect of the severe unspecific inflammatory cascade, this appears to be difficult, since this cascade is irrelevant in SARS-CoV-2 asymptomatic patients. If instead they suggest that the virus could activate the production of Abs against a myelin protein structurally similar to one of viral proteins, this might certainly be a fascinating assumption, which would, nevertheless, require a more precise knowledge of such a peptide sharing.

We are grateful to our French and Swiss colleagues to have shared the observation of this cluster.

The possibility of immunologic sequelae after a contact with the virus raises some serious concerns for neurologists, especially considering the appearance of a possible new peak of the pandemic curve [12]. We think that epidemiological studies based on large nationwide and international databases are needed to evaluate the exact incidence of GBS cases during and after the pandemic.

Funding None.

Data access, responsibility, and analysis The corresponding author had full access to all the data in the study and takes responsibility for the integrity of the data and the accuracy of the data analysis.

\section{Compliance with ethical standards}

Conflicts of interest On behalf of all authors, the corresponding author states that there is no conflict of interest.

Ethical approval This study followed the tenets of the Declaration of Helsinki and was performed according to the guidelines of the Institutional Review Board of University of Udine Medical School.

\section{References}

1. Gigli GL, Bax F, Marini A et al (2020) Guillain-Barré syndrome in the COVID-19 era: just an occasional cluster? J Neurol. https ://doi.org/10.1007/s00415-020-09911-3

2. Tatu L, Nono S, Gracio S, Kocer S (2020) Guillain-Barré syndrome in the COVID-19 era another occasional cluster? J Neurol (Ahead of print)

3. Coen M, Jeanson G, Culebras Almeida LA et al (2020) GuillainBarré syndrome as a complication of SARS-CoV-2 infection. Brain Behav Immun. https://doi.org/10.1016/j.bbi.2020.04.074

4. Lascano AM, Epiney J-B, Coen M, et al SARS-CoV-2 and Guillain-Barré syndrome: AIDP variant with favorable outcome. Eur J Neurol. https://doi.org/10.1111/ene.14368

5. Riva N, Russo T, Falzone YM et al (2020) Post-infectious Guillain-Barré syndrome related to SARS-CoV-2 infection: a case report. J Neurol. https://doi.org/10.1007/s00415-020-09907-z

6. Toscano G, Palmerini F, Ravaglia S et al (2020) Guillain-Barré Syndrome associated with SARS-CoV-2. N Engl J Med. https:// doi.org/10.1056/NEJMc2009191

7. Tan Y-J, Goh P-Y, Fielding BC et al (2004) Profiles of antibody responses against severe acute respiratory syndrome coronavirus recombinant proteins and their potential use as diagnostic markers. Clin Diagn Lab Immunol 11:362-371. https://doi. org/10.1128/CDLI.11.2.362-371.2004

8. Meyer B, Drosten C, Müller MA (2014) Serological assays for emerging coronaviruses: challenges and pitfalls. Virus Res 194:175-183. https://doi.org/10.1016/j.virusres.2014.03.018

9. Long Q-X, Liu B-Z, Deng H-J et al (2020) Antibody responses to SARS-CoV-2 in patients with COVID-19. Nat Med. https://doi. org/10.1038/s41591-020-0897-1

10. Wu F, Wang A, Liu M et al (2020) Neutralizing antibody responses to SARS-CoV-2 in a COVID-19 recovered patient cohort and their implications. medRxiv. https://doi.org/10.1101/2020.03.30.20047 365

11. Wu L-P, Wang N-C, Chang Y-H et al (2007) Duration of antibody responses after severe acute respiratory syndrome. Emerg Infect Dis 13:1562-1564. https://doi.org/10.3201/eid1310.070576

12. Neher RA, Dyrdak R, Druelle V et al (2020) Potential impact of seasonal forcing on a SARS-CoV-2 pandemic. medRxiv. https:// doi.org/10.1101/2020.02.13.20022806 